\title{
Green Energy Saving Practice of the New Village Construction-Taking the Green Design of Wangyu Village, Qin Huangdao City as an Example
}

\author{
Dong Yuan, Ning Wang, Chunyang Ou \\ Urban and Rural Planning, \\ Agricultural University of Hebei, \\ Hebei, China
}

\begin{abstract}
As a kind of sustainable development mode, energyefficient building and green design is not only the ideal way of the new rural development of China in the future, but also the direction of the world's development. When taking the green energy-saving design practice and application of the new rural construction as an illustration in this paper, it turns out that the energy-efficient building and green design has broad prospects and typical meanings in the new rural construction. Wang $\mathrm{Yu}$ is the demonstration village of the new rural construction in Hebei province. The rainwater harvesting, waste-water treatment, gray water utilization, natural landscape of water fall, building energy conservation and biogas utilization, etc. in Wang Yu, everything without exception annotate the significance of the green design and green construction.
\end{abstract}

Keywords-green design; green building; green landscape; green walkways

\section{INTRODUCTION}

With the global energy crisis and environmental pollution, Countries around the world are constantly developing energy saving technology to alleviate the country's energy shortage and environmental pollution situation. Energy-efficient building and green design is based on environmental protection and energy saving [1]. Green design can enhance the development of urban and rural planning and construction, the efficiency of energy utilization, and the achievement of "Chinese dream, beautiful countryside” blueprint.

\section{PRESENT OF ENERGY-SAVING BUILDING AND GREEN DESIGN}

Building energy-saving in our country started relatively late compared with the developed countries, and has many problems, such as legislation is not perfect, rational energy use standard civil vacancies, lack of appropriate operation of the building's energy efficiency standards for running heating and air conditioning systems [2]; management institutions are not perfect, because of the lack of effective policy measures, the corresponding energy conservation organizations and relevant responsible units, resulting in proceeds slowly building energy efficiency; green design concept is not universal, green energy-saving building design is far from reaching the level of popularity [3]. Energy-saving technologies and products are not mature enough and the construction and promotion of energysaving building methods scarcity, etc.

\section{SIGNIFICANCE OF ENERGY-SAVING BUILDING AND GREEN DESIGN}

Currently China is affected by the lack of resources of land, forestry and oil, and the planning and construction of urban and rural construction projects need to consume a lot of resources. So energy-saving buildings and green design in the period of rapid development of China's urbanization is utmost necessity and importance.

Urban and rural planning and construction works in the building construction, not only consumes a lot of energy, but also emit large quantities of different forms of pollutants. Therefore, in process of saving energy, reducing emissions and protecting the environment, we must develop new construction techniques to improve urban and rural planning and engineering construction for safety, reliability, environmental protection and economy, while the use of green building and green design can well to achieve these objectives [4].

\section{APPLICATION OF ENERGY-SAVING BUILDING AND GREEN DESIGN IN THE NEW VILLAGE}

\section{A. Green design}

- $\quad$ Subsystem the rainwater collecting and processing

Independent rainwater pipe network system, there are many energy saving features:

(i) Rainwater systems are gravity discharge, namely no powered drainage.

(ii) In the case of complex terrain slope change, in order to reduce the drainage pipeline, the adopts fragmentation collection.

(iii) Between the north area and the mountains in the village, they set cut intercepting flood ditch. In order to reduce the project cost, they adopt the open channel section Intercepting flood ditch.

(iv) Rainwater recycling design: cross-sectional intercepting flood ditch and drainage system are linked together, which terminates rapidly into the village ditch and $\mathrm{Xu}$ Shuitang. Features: The rain works as a plunge landscape, creates a good ecological environment, and irrigates by collecting and storing rainwater in the dry season. 


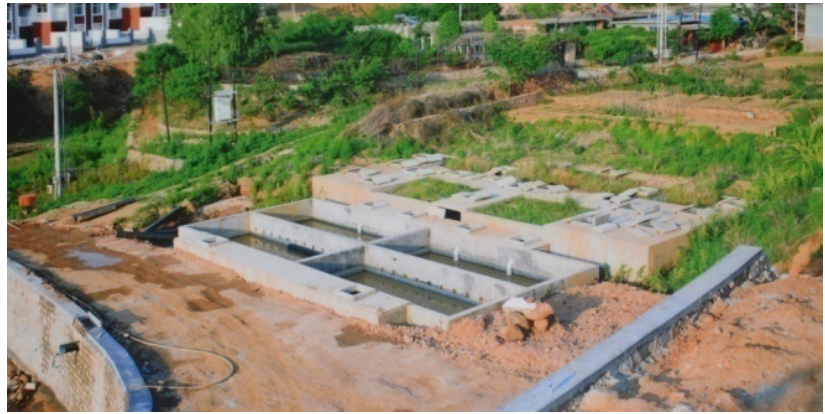

Figure 1. No powered sewage treatment system.

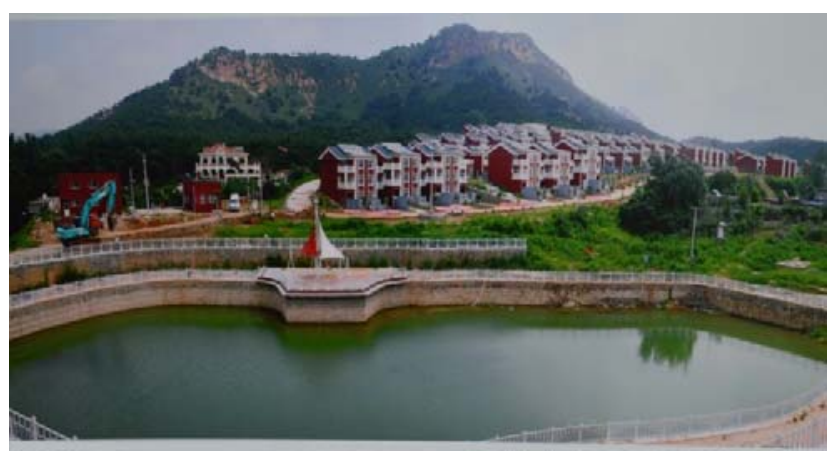

Figure 2. Pool of reclaimed water reuse.

- Subsystem sewage treatment

(i) Setting small sewage treatment facilities: to protect the ecological environment and Yan San lake from pollution, the small sewage treatment facilities are set at low-lying place of the village's west, such as Figure 1.

(ii) Sewage treatment facilities collected the whole village sewage which is treated by biological filter. Sewage treatment meet the current "integrated waste-water discharge standard" requirement, naturally flowing into the landscape water system in the village.

- Reuse of reclaimed water

Sewage recycling: sewage is discharged to sewage treatment station, by dealing with, and then is recycled.

Reclaimed water is used to irrigate the village green, vegetation, agricultural ecological sightseeing park, highstandard facilities agriculture and large cherry plantations, and used as a water landscape, such as Figure 2.

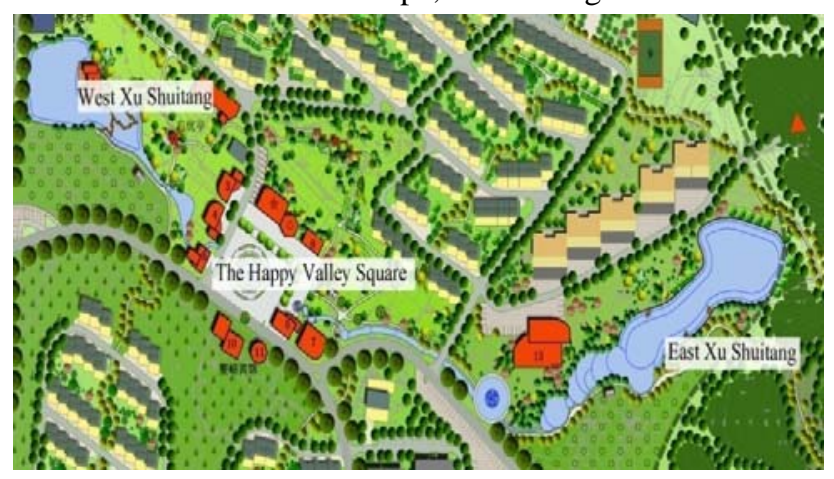

Figure 3. Pool of reclaimed water reuse.
- Landscape of water fall

No powered exists landscape: village landscape water system is equipped with three plunge landscapes, which adopt the gravity drainage, mainly using 17 meters elevation difference of the village between the two $\mathrm{Xu}$ Shuitang. To avoid water scouring the over-consumption of channel, the hydraulic calculation that need to set up three down Wells, highly consuming the potential energy of gap between water, which will be well design for folding water landscape, such as Figure 3, and reflects the characteristic of green design.

\section{- Green walkways}

(i) Green walking trails: independent walking system is designed, not only for people to walk, but also for people to exercise physical, enjoy the scenery, relax mood, Cultivate temperament and exchange feelings. There is greening, road, fitness equipment, garden and building sketch, etc.

(ii) Separation of pedestrian and vehicular traffic: village road system using the pedestrian and vehicular traffic humanized design, this situation ensures that each group of residential house has opened to traffic and behind the house has a pedestrian road.

\section{B. Energy saving design}

- Energy saving building

(i) Green energy-saving building design, not only contains the walls, roofs, doors and Windows, floors and other architectural elements, also reflects in the application of new technology in energy saving as well as the overall layout of the terrain.

(ii) The main body of the wall is laid by energy saving bricks and hollow wall again is laid by new benzene plate heat preservation material $9 \mathrm{~cm}$ thick; outside the window we use hollow glass Windows and the gap between the glass which is filled with inert gas, in order to obtain good heat preservation, heat insulation and sound insulation performance; Door plank uses eight thick thermal insulation door plank. 


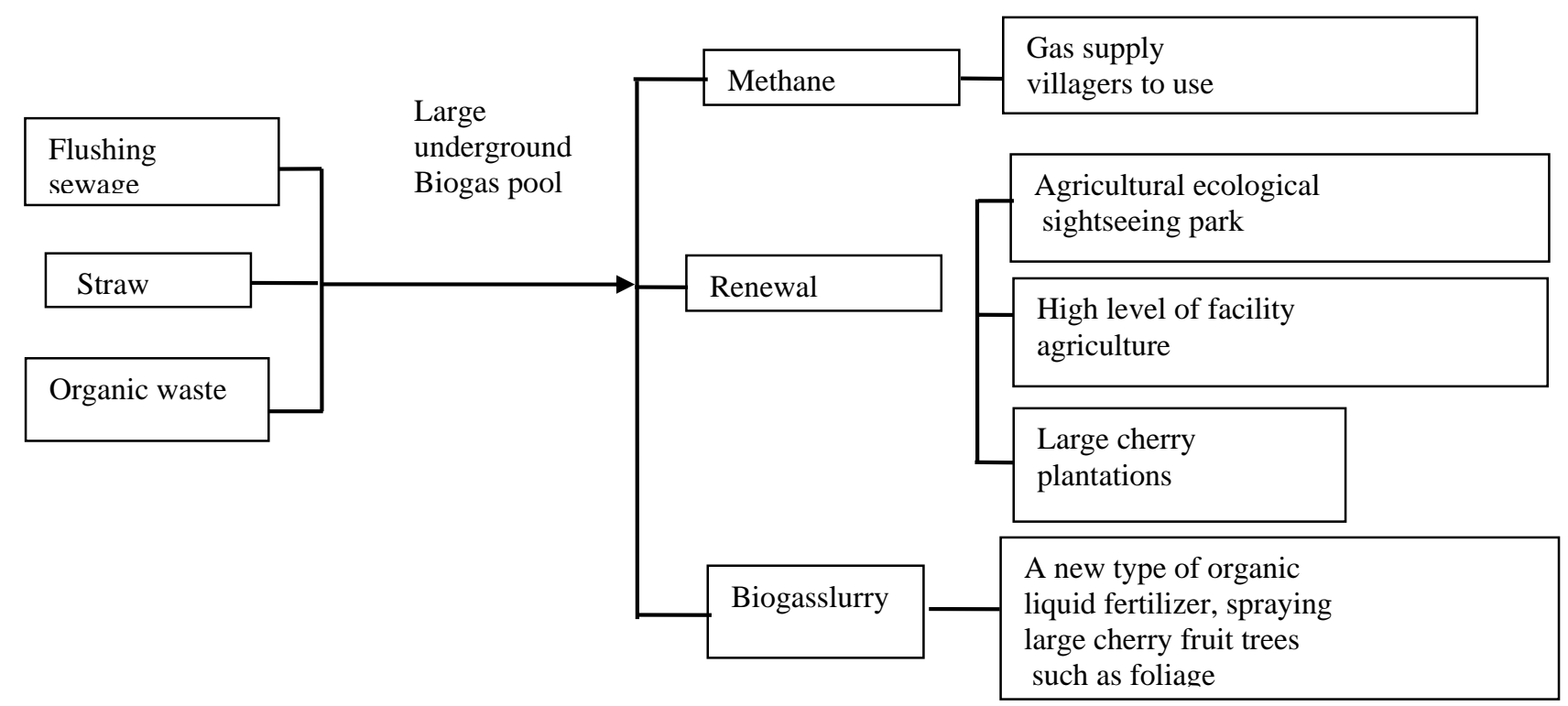

Figure 4. Bio-gas using flow chart.

- $\quad$ Energy saving heating system

Winter heating $=$ solar + thermal insulation wall + heated wall + straw gasifier + floor heating coil + electric auxiliary

Planning the heating engineering is given priority to with solar energy, and straw gasifier, heat preservation wall, heated wall and floor heating coil are complementary. The selected solar heating facilities and auxiliary power unit, when it's cloudy or indoor temperature does not meet the requirements of users, we can start the electric heating system and make indoor temperature meet the requirements.

- Bio-gas utilization (Figure 4)

- High efficient land utilization

New village site using the barren land of Chang Qiaodian village, will merge the Xin Jian village, Shang Gou village, Xia Gou village, Wai Yu village and Chang Qiaodian village five villages, not only to save the land, but also to improve land utilization.

TABLE I. A VILLAGE CONSTRUCTION LAND LiST BEFORE AND AFTER THE MERGER.

\begin{tabular}{|c|c|c|}
\hline Village Name Index & Construction Land & Total (ha) \\
\hline Xin Jian village & 9.49 & \multirow{2}{*}{34.03} \\
\cline { 1 - 2 } Shang Gou village & 3.78 & \\
\cline { 1 - 2 } Xia Gou village & 6.96 & \\
\hline Wai Yu village & 8.81 & \\
\cline { 1 - 2 } Chang Qiaodian village & 4.99 & 17.70 \\
\hline Wang Yu village & 17.70 & 16.33 \\
\hline Saving the land & - & \\
\hline
\end{tabular}

Merged village adopts stock management, restoring the construction land to agricultural land, optimizing large cherry industry, improving the tourism industry, developing the characteristic agriculture and realizing the efficient utilization of land. Under the protection of cultivated land and the premise of protecting farmers land rights and interests, and through the implementation of the rural planning and construction, we explore a way that can enhance land utilization and improve farmers quality of life (Table I).

\section{THE PROSPECT OF THE ENERGY-SAVING BUILDINGS AND GREEN DESIGN}

Building energy efficiency and greening design based on the energy saving, health, environment and the humanities, emphasis on integrity, openness, efficiency and intelligence. At present, our country is in a new urbanization rise period, especially the rapid development of small towns and new rural areas[5]. Energy-efficient building and green design not only plays an important role in energy conservation and consumption reduction, but also has realistic and far-reaching significance in realizing the sustainable development of our economy and society. In the new urbanization construction period, energy-efficient building and green design has considerable prospects.

\section{REFERENCES}

[1] Youyou Wang, Building energy conservation and new energy utilization. Jiangxi Materials, 1, 2001.

[2] Rima Fayaz, Behrouz M. Kari, Comparison of energy conservation building codes of Iran, Turkey, Germany, China, ISO 9164 and EN 832. Applied Energy, 86, 1949-1955, 2009.

[3] J. Smeds, M. Wall, Enhanced energy conservation in houses through high performance design. Energy and Buildings, 39, pp. 273-278, 2007.

[4] Xu Xinguang, Green buildings building energy [A]. Shanxi Architecture, pp. 1009-6825, 2009, j23-0248-02.

[5] Yang Hailin, Greet the Arrival of the Era of Green Building. Heilongjiang Science and Technology Information, 33, 2008. 